\author{
DESIGN OF THE FERMILAB \\ REMOTE TARGET MAINTENANCE SYSTEM*
}

Ju1y 1975

John Simon, John Grimson

Jack Lindberg and Dennis Theriot

${ }^{*}$ To be presented at $23 \mathrm{rd}$ Conf. on Remote Systems Technology Winter Meeting, American Nuclear Society, Nov. 16-21, 1975, San Francisco, Calif. 


\begin{abstract}
A system of interchangeable targetry on rail transporters has been in use for four years. This design concept allows rapid interchange of radioactive target equipment with a minimum of exposure to operating personnel. Separate maintenance facilities equipped with a variety of remote handling equipment, including a mobile electric master slave manipulator, are used to construct, maintain and modify targetry and beam line equipment concurrent with the $400 \mathrm{GeV}$ accelerator beam operation.
\end{abstract}


The Fermi National Accelerator Laboratory Target Handling and Maintenance system is unique in design when compared to most existing accelerator facilities. The principle of interchangeable components on which it is based is certainly not new, since it is used. widely in industry and the use of rail systems to transport radioactive equipment to service facilities was used in both the Mercury and Nerva projects. However, it is the first to utilize effectively the advantages of the most dexterous and rapid, large space, manipulating system which has been developed and manufactured up to this time.

Early design concepts for the Fermi Accelerator 1, 2, 3, 4 were based on existing machines, where targets are housed in huge halls, covered by kilotons of concrete shield blocks. Access to such targetry involved the use of an equally huge crane to remove and replace the shielding. It also resulted in serious radiation exposure to the operators, and worst of all, complete and lengthy shutdown of experiments.

Two important considerations determined the design requirements of this system; first, interruptions to the experimental program are very costly in terms of capital and hourly operating charges, as well as the experimenters time. Secondly, Energy Research and Development Administration (ERDA) and Laboratory poli- 
cies dictated the lowest possible radiation exposure to operating personnel.

Since the much higher energy and intensity of this accelerator would greatly magnify the problems, the radiation levels, the exposure, and the pile of shielding blocks, another approach was needed. ${ }^{5}$ The maximizing of beam time for experiments and minimizing the cost and handling of shielding is accomplished by an earth shielded target tube and interchangeable targetry, mounted on trains, which are placed within the tube. This system, ${ }^{6}$ allows rapid interchange of targets and associated beam line equipment. It permits rapid recovery from failures and also provides a convenient method of varying the beam characteristics for different experiments, without duplicating facilities.

Manual and remote target maintenance for both the Neutrino and Proton target areas of the Laboratory is now carried out in two shielded enclosures, which are separate and shielded from the operating target enclosures. Each is equipped with a variety of handling and viewing equipment which allows the construction and maintenance of targetry to be carried on concurrent with beam operations.

Normally all low level work is done manually while most work in fields of $250 \mathrm{MR} / \mathrm{hr}$ (at one foot), and above, is presently carried out with the manipulators. 
However, because of the additional time required to do remote operations, the remote equipment is used initially to remove, or place shields around, areas of high activity. Men may then enter the building and perform the work in the lower radiation areas, while the manipulator continues with high risk work. Small equipment is worked on in a secondary remote enclosure after removal from the trains. When equipment has been completed in this manner, and schedules indicate, an interchange can be made rapidly. As little as 8 hours of down time and 3 man-rem exposure are involved in such a transfer.

Separation of the operating and the repair/construction areas, plus the provision of alternate target equipment reduces the pressure, the size of the work force, and allows more rational control of the radiation exposure to operating personnel. This serves to lower the overall biological exposure to the lowest practical level.

The Neutrino Target Service Building (TSB), a $26^{\prime} \mathrm{W}$ x $18^{\prime} \mathrm{H}$ x $8^{\prime} \mathrm{I}$ windowless concrete structure, was designed to be tornado proof to meet ERDA requirements, It is used as the primary construction, repair, and modification area for neutrino target trains and proton target drawer units. Similar operations on meson area targetry are anticipated in the future. Proton and 
meson equipment however, must be transported by truck since no rail connection exists at this time.

The major pieces of handling equipment in the building are a 20 ton crane and an Argonne Mark IV Electric Master Slave Manipulator' installation. The crane and manipulator are mounted on separate overhead bridges, but operate on the same set of rails (see Figure 1). Both can be operated remotely from a control room 40-ft. outside the shielded area. The crane is also provided with local control for use during manual operations.

Two TV cameras, equipped with zoom lenses and pan and tilt supports are mounted at opposite corners of the building. These provide overall surveillance of the space during remote movements of the crane and manipulator. A continuous, remote indicating, radiation monitoring system covers all major areas of the facilities. An elevated surveyors work station with permanent equipment traverse bar is instailed at the south end of the TSB. Alignment of radioactive components can be made from this point, at a distance of 50 to 150-ft. from the work, utilizing the manipulator to make the necessary adjustments.

The building contains two 30 " gauge rail tracks which extend into a $230-\mathrm{ft}$. long storage tunnel to the south. (Figure 2 shows the building and tunnel during 
construction.) A single track tunnel extends north west connecting with the track in the target hall (Neuhall). An additional track extends north into a 130-ft. long addition to the TSB now under construction. This extension will permit work at any point on a 200-ft. long train without moving it, and also provide the facilities for testing the beam equipment prior to installation in the target tube. It will also provide additional storage space for radioactive proton, meson, and neutrino equipment.

The manipulators now in use are the prototype units developed by the Remote Control Division of Argonne National Laboratory. They are substantially the same as originally built, except for some modernization of the transistor servo amplifiers. A second pair of both master and slave arms (Central Research Labs, Model M), but excluding electronics, were purchased for use in a second facility. Fully modernized transistor amplifiers are now being fabricated for use with these units.

Since the manipulators were acquired substantially complete, our major design effort was directed toward an adequate mobile mount and viewing facilities. Consideration was given to floor and wall mounting, but overhead bridges were selected as being most suitable for the load configuration and interfered least with other features of the building, such as doors, windows, 
and mechanical manipulator installations (see Figure 1). In addition, since the same rails are used for both manipulator and crane bridges, a substantial saving in rail, rail supports and additional ceiling height results. The major disadvantage of this arrangement is that the manipulator cannot directly engage the hook of the 20-ton crane which was selected to meet other non-remote requirements.

The in-cell portion of the manipulator unit consists of a pair of slave servo manipulator arms mounted on a bridge, carriage, and rotating turret (see Figure 3). The manipulator arms move $5-\mathrm{ft}$. on a vertical post attached to the turret. By this combination of elements, the arms can reach about $85 \%$ of the floor area of the building from the floor to approximately 10-ft. high and approach most work from any angle. Primary viewing of the manipulator arms and work area is provided by two high resolution ( 1000 line) TV cameras mounted under the body of the right hand manipulator slave. These are mounted side by side and slewed by a high speed, positional servo, pan and tilt system. One camera is equipped with an f2, 18 to $90 \mathrm{~mm}$ zoom lens, providing a detailed magnified view of the work; the other with an fl.4, $6 \mathrm{~mm}$ fixed super wide angle lens, which provides full coverage of the entire space reached by the manipulator tongs. 
A third conventional TV camera mounted on the turret, facing down, gives a plan view of the manipulator arms and operating area. A 2-ton, two speed electric hoist is also mounted on the turret, located to permit lowering its chain between the manipulator arms.

The bridge system utilizes variable speed drive motors for both bridge and carriage motions. Two conventional TV cameras are mounted on pan and tilt units at opposite corners of the bridge to provide traveling overall views of manipulator work and motion clearances. Looped messenger, power and control, cables are used to supply both the bridge and manipulator.

A variety of small power and hand tools are provided for use by the manipulator. These include air and lectric impact wrenches, tubing nut wrenches, and power thears, as well as hand box, end, ratchet and socket wrenches. Many have been modified to provide grips which are more compatible with the manipulator tongs and with extensions to switches to simplify reversing. AIl of the power tools are controlled from the manipulator control center. The tools are stored in a rolling tool caddy (see Figure 4) which can be placed in the vicinity of the work. Permanent lifting slings allow the manipulator to move it easily to other locations. The power tools and numbered sockets are stored and arranged in numbered holders to simplify their use and 
exchange. A counter-balance is used with the heavy power tools to increase maneuver-ability and feel during engagement.

The crane is a standard commercially built unit except that it employs variable speed drives on the bridge and trolley motors. These were specified to reduce swinging of the load when positioning equipment accurately during remote assembly operations. A specially designed wall rack holds a variety of chain slings which are positioned to allow direct pick-up or return of slings by the crane hook. A variety of other slings, hooks, and spreader bars are provided for specific load requirements such as bending magnets and bedplates.

Principle dimensions and capacities of the manipulator, bridge and crane are given in Table 1.

The remote operating station for the manipulator, crane and other equipment in the TSB is temporarily located in a portable building $40-\mathrm{ft}$. away from the TSB. Access to the cell area is through a second portable building provided with a standard arrangement of hand and foot monitors, showers, toilets, change room and lockers.

Two men are required for normal operation of the TSB remote handling equipment. One operates the master arms of the servo manipulator, the auxiliary tooling, 
and the servo controlled pan and tilt motions of the main TV cameras. This control is accomplished by the rotation of the seat, and the tilting of the back rest, of the chair on which the operator sits. TV views of the work and the cell are displayed on four monitors arranged as shown in Figure 5 . The simultaneous close-up and wide angle, high resolution camera views are displayed on the two 21 " monitors at the bottom. Views from any two of the other five cameras can be switched onto either of the two 17" monitors at the top.

The second operator controls the manipulator and crane bridge motions, the auxiliary TV pan and tilt motions and all TV zoom, focus, and picture adjustments from a control panel behind and to the side of the primary operator. It is expected that these two men will work closely as a team. The second man must aid, advise, and anticipate the needs and desires of the primary operator. We have not fully explored the problems and potentials of this relationship.

The trains ${ }^{6}$ are essentially two piece narrow gauge railroad flat cars, consisting of a bedplate and a transporter. Each of the transporters is a box-like, stiffly sprung, four wheeled car, which carries the equipment bedplates. It is $20^{\prime}$ from coupler to coupler. The bedplates vary from 18' to 19'6" in length depend- 
ing on equipment requirements, and are equipped with spacer tongues or buffers which maintain the $20^{\prime}$ spacing. Each is designed to carry 40 tons of equipment, and is provided with 2 sets of hydraulic cylinders which are used to lift and align the bedplate loads. None of the cars however, are equipped with brakes since the entire roadbed is now level. The trains are moved by a 6 ton diesel powered mine type locomotive which is manually controlled. Due to the limited trackage and turn-around space for four trains, which causes the locomotive to be trapped, a rubber tired tow vehicle is also used. Two surplus battery operated mine type locomotives are being modified, and will be equipped for remote control, to replace the existing equipment shortly.

The smaller secondary enclosure is a temporary, open topped room, located inside an industrial building. It is constructed of $3^{\prime}$ thick shielding blocks (see Figure 6), approximately $30^{\prime} \mathrm{W} \times 60^{\prime} \mathrm{L} \times 9^{\prime} \mathrm{H}$. It is used to carry out further maintenance operations on small components removed from the target trains in the TSB. Both remote and manual work is done, dependent on radiation levels, usually in the same order. Since this is a temporary facility, it is not fully equipped. However, it has one window manipulator station consisting of two 2' $x 3^{\prime}$ all glass shielding windows, and a 
pair of heavy duty mechanical manipulators. Temporary lines also provide air and electricity for impact and other power tools. Lights and hoists are usually rigged as needed.

The functions and equipment of this facility will be expanded and incorporated into the extension to the TSB now under construction. It then will include a second mechanical manipulator station as well as a second electric servo-manipulator and a crane. When completed, this area will eliminate truck shipment of radioactive components between facilities and provide expanded capacity to handle targetry from the Proton and Meson areas.

Small work will normally be placed on standard bedplates and cars shunted in front of the mechanical manipulator window station. In some cases, the equipment, such as proton drawers, will be placed on special bedplates equipped with removable steel sides and covers. These completely enclose the equipment for storage or can be selectively removed to partially uncover the work. This procedure simplifies the integration of manual and remote operations, and allows scheduling of a variety of jobs of different priorities in the same work area.

Planning and building the remote handling facilities and equipment is only a part of the task of 
successful maintenance of radioactive equipment. Intelligent, resourceful design of the equipment which is to be maintained is also vital.

Much of the radiation exposure our operators receive at present is caused by equipment hurriedly installed on our first train, a temporary unit which is now 3 years old. None of this equipment was expected to get radioactive and little effort was expended to make it easily removable and accessible. As a consequence, repair or removal of equipment is frustratingly slow and difficult, even when done manually.

By contrast, during a recent 24 hour remote disassembly operation on this equipment (see Figure 7), the operators received only a total of 0.2 man-rem exposure. Most of this was received manually removing bolts thoughtlessly placed under one of the pieces of equipment. While even this operation could have been carried out remotely, it required removal and replacement of two adjacent piecés of equipment at considerable expense of time and was judged impractical because of the overall time available. Radiation exposure for this job had been estimated previously to run from 8 to 15 man-rem, if done manually. The remote operation therefore reduced exposure by a factor of at least 40 .

Since the original train was built, three additional trains have been constructed. These are the Triplett, 
Horn, and Hall trains. ${ }^{6}$, Each of these designs incorporate improvements which materially affected the ease of assembly, set up, adjustment, and removal of the target components.

We have found that it is not necessary to use elaborate designs to achieve this end. Many of the following design measures have been used in the construction of our new equipment and have been found highly successful and profitable:

I. We use a limited number of bolt sizes by elimination of intermediate $1 / 16^{\prime \prime}$ sizes such as $5 / 16,7 / 16,9 / 16$, etc. This reduces the number of tools and tool changes necessary for any manual or remote operation.

2. Only coarse screw thread series are used to avoid intermixing and crossthreading during hurried reassembly.

3. A minimum number of fasteners are used. In most cases, two are adequate and one, of a clamp or wedge type, even better. Most standard head and drive shapes are acceptable providing the tool slips on easily and stays put. We avoid particularly plain slotted screws or hexagon (Allen) 
socket screws. Phillips slotted and standard hex head bolts are far better. When recessed or counterbored or high strength screws are required, we use 12 point external spline bolts and/or nuts (Manufactured by Ferry Cap Counter-Bor Screw Company, and Standard Pressed Steel Company). These are readily available, standard, and no more expensive to substitute.

4. A means for lifting is provided. A tapped hole for an eye bolt is good but permanently fastened sling hooks or holes for hooks or pins are better.

5. It is desirable to separate the locating and fastening functions. Guide pins or surfaces can be provided for locating; with one or two bolts provided for fastening. In many cases, the bolts can both locate, and fasten, by using slots or keyholes, and only a full turn is required to engage or disengage. When guide pins are provided, only 
one is cylindrical, the other is flatted or diamond shaped and the locating band or surface is only $1 / 8$ " to $3 / 16 "$ high to avoid jamming when assembling the parts.

Remote operations, involving radioactive equipment began December 15, 1975 and have included successful removal and disassembly of targets, target drives, instrumentation, and a Neutrino focusing horn. Other duties, such as wrapping of contaminated equipment and vacuum cleaning of bedplates to remove radioactive dust and paint chips, have also been carried out. The system and procedures described have reduced personnel exposures from 80 to $95 \%$, even during these early imperfect operations.

When compared with most existing comparable facilities or installations, the manipulative equipment we have selected seems complicated, sophisticated, and expensive. At least, that is what critics of general purpose manipulators have always said. However, we knew from past experience that we could have little prior influence on the design of experimenters equipment and must be ready to replace or repair any type of device which may come along. Because of this, the most dexterious general purpose manipulator was a necessity. Naturally, we had to convince our management that this was the 
case. As in the past, initial cost of the handling equipment was a prevailing consideration.

However, one must consider overall costs and results before making a decision, 9,10 and in our case it was. We were able to show that the money saved in capital cost, is expended many times over, in design and construction costs to build special purpose machines and fixtures; whose sole function is to augment (and make up for) the poor speed and dexterity of the handling equipment selected. Furthermore, these special devices suffer from a whole set of unique shakedown and servicing problems because they have not had extensive operating tests and development. In contrast, the Argonne Mark III Servo-Manipulators had a successful 7 year hot-cell operating history, and commercial manipulators have proven their reliability in hot-cells all over the world, when properly used.

It is our belief that this system or one similar to it 11,12 could be used successfully to perform most reactor maintenance servicing operations, if management was forthright enough to realize the advantages of this approach. Naturally, some concessions would have to be made. The traditional designs of steam power plants would have to be advanced to permit easier servicing, whether by man or machine. Provisions would have to 
be made to shut down sectors of the reactor while being serviced, or portions of it made into removeable modules. Valves and other components must be designed to snap in and out or be remotely serviceable.

We have shown the remote servicing operations on large industrial type equipment are feasible. There is no reason why others cannot do the same, to solve one of the serious problems in Nuclear Power's future.

\section{ACKNOWLEDGEMENT}

The Fermi National Accelerator is operated by the Universities Research Association, Inc., under contract with the U.S. Energy Research and Development Administration. 
R E F E R E N C E S

1. "Remote Maintenance Techniques Proposed for the $200 \mathrm{GeV}$ Accelerator," by R. Krevitt, Lawrence Radiation Laboratory IEEE Transactions on Nuclear Science (June, 1967), p.997.

2. "Capability vs Cost for Servicing and Handling System Choices in $200 \mathrm{BeV}$ Accelerator Desigh Study," by W. Salsig, Lawrence Radiation Laboratory IEEE Transactions on Nuclear Science (June, 1967), p.887.

3. "Radiation Problems with High-Energy Proton Accelerators," by W. Gilbert, Lawrence Radiation Laboratory IEEE Transactions on Nuclear Science (June, 1967), p.965.

4. "200 BeV Design Study," Vol. II, Lawrence Radiation Laboratory, University of California.

5. "Target Handling System for the $200 \mathrm{GeV}$ Proton Accelerator," by J. Grimson, J. Lindberg, A. Maschke, J. Simanton, and J. Simon. Proceedings of 18th Conference on Remote Systems Technology (1970), p.135.

6. "Fermilab Target Areas and Target Train System," by J. Lindberg, J. Simon, J. Grimson, and D. Theriot. Proceedings of $23 x d$ Conference on Remote Systems Technology. (1975) 
7. "Argonne National Laboratory Mark E4A Electric Master-slave Manipulator," by R. Goertz, J. Grimson, C. Potts, D. Mingesz, and G. Forster. Proceedings of 14 th Conference on Remote Systems Technology, ANS (1966) p.115.

8. "Design of the Fermilab Neutrino Horn Train System Referenced to Radioactive Maintenance," by J. Grimson, J. Lindberg, J. Simon, and D. Theriot. Proceedings of $23 r d$ conference on Remote Systems Technology. (1975)

9. "Induced Radioactivity and Remote Handling Methods for Accelerators," by A. Gorka, Particle Accelerator Conference, Washington, D.C. (March 10-12, 1965).

10. "Remote-Handling Philosophy and Equipment for LAMPF," by M. Wilson, Los Alamos Scientific Laboratory, "Private Communication" MP-6/MW-2 (July, 1968)

11. "Development of Servo Manipulators for High Energy Accelerator Requirements," by C. Flatau. Proceedings of the 13th Conference on Remote systems Technology, ANS (November, 1965).

12. "A Compact and Flexible Servosystem for Master-slave Electric Manipulators," by I. Galbiati, C. Mancini, T. Raimondi, and F. Roncaglia. Proceedings of the 12th Conference on Remote Systems Technology, ANS (November, 1964) 
TARGET SERVICE BUILDING

EQUIPMENT SPECIFICATIONS

Craneıand Bridge Travel.........................

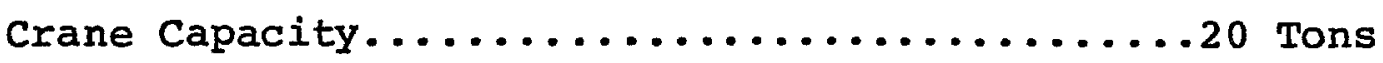

Hook Height Maximum (15-ft. travel)..........13-Ft.

Hook Height Minimum.................... Ft.

Crane Bridge width.............................

Crane Rail Height...................12' 10-Inches

Manipulator Bridge width................25-Ft.

Carriage size....................... square

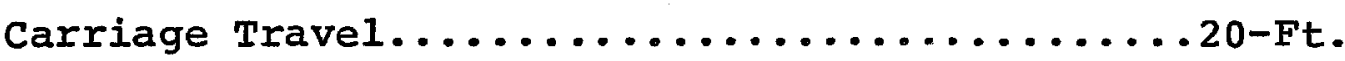

Turret Rotation......................... 450

Post size........................7-7/8 square

Post Vertical Travel..................... Inches

Manipulator Vertical Travel............60 Inches

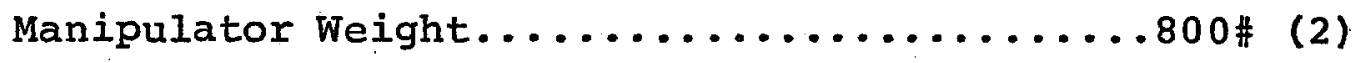

Turret Hoist Cap..................... Tons

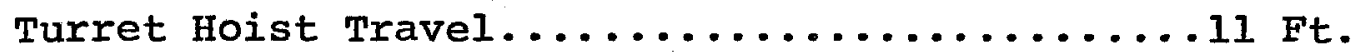

Total Manipulator and Carriage Weight.....4000\#

Total Load on Bridge................8000\#

Total Bridge Weight $w / 2$ Ton Load on Hoist. $11439 \#$

Bridge speed.......................6-66.4 FPM

Carriage speed........................40 FPM

Manipulator Hoist Speed....................... FPM

Load Hoist speed (High) ................. FPM

Load Hoist speed (Low) .................. 7 FPM

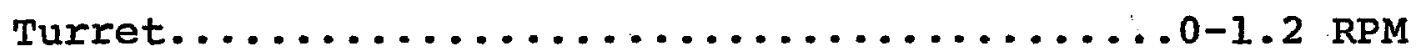

Crane Bridge speed...0-70 Ft/min. (load) $100 \mathrm{ft} / \mathrm{min}$. no load

Trolley(Carriage) speed ..0.30 Ft/min.(load) $100 \mathrm{ft} / \mathrm{min}$. no load

Trolley Hook speed (Max) .. $\frac{1}{4}-4 \mathrm{Ft} / \mathrm{min}$ (load) $100 \mathrm{ft} / \mathrm{min}$. no load 


\title{
FIGURE TITLES
}

for

FERMILAB REMOTE TARGET MAINTENANCE

\author{
Figure 1 - - Remote Handling Equipment in Fermilab \\ Target Service Building. \\ Figure 2 ---- Target Service Building Under Construc- \\ tion with storage Tube in Foreground. \\ Figure 3 - - Bridge Mounted Electric Master Slave \\ Manipulators. \\ Figure 4 ----- Tool Caddy used with Servo Manipulator \\ Figure 5 ---- Servo Manipulator Master Operating \\ station. \\ Figure 6 ---- Interior of Secondary Maintenance \\ Facility Manipulator-Window station. \\ Figure 7 ---- Servo Manipulators being used to \\ Disassemble Radioactive Equipment.
}




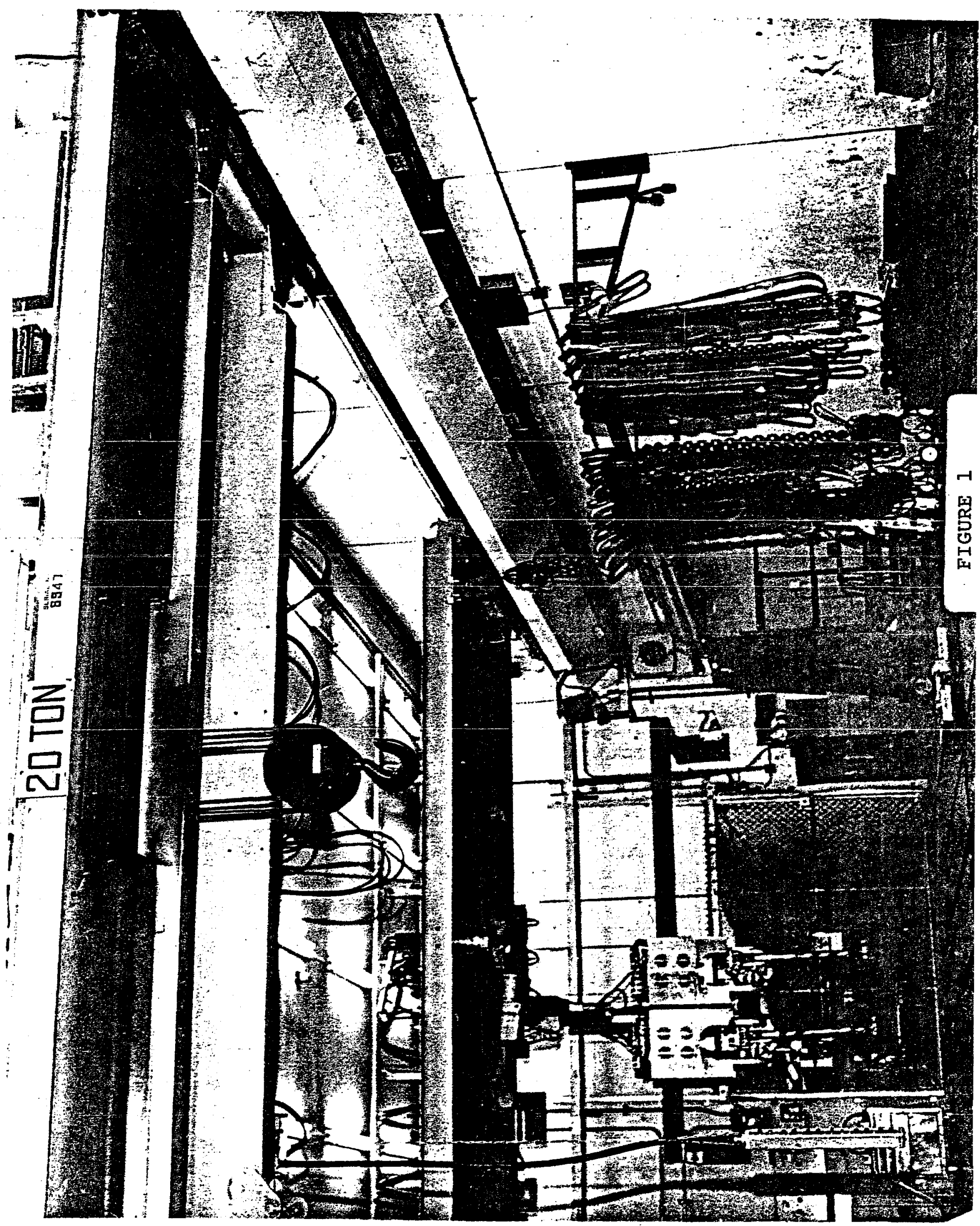




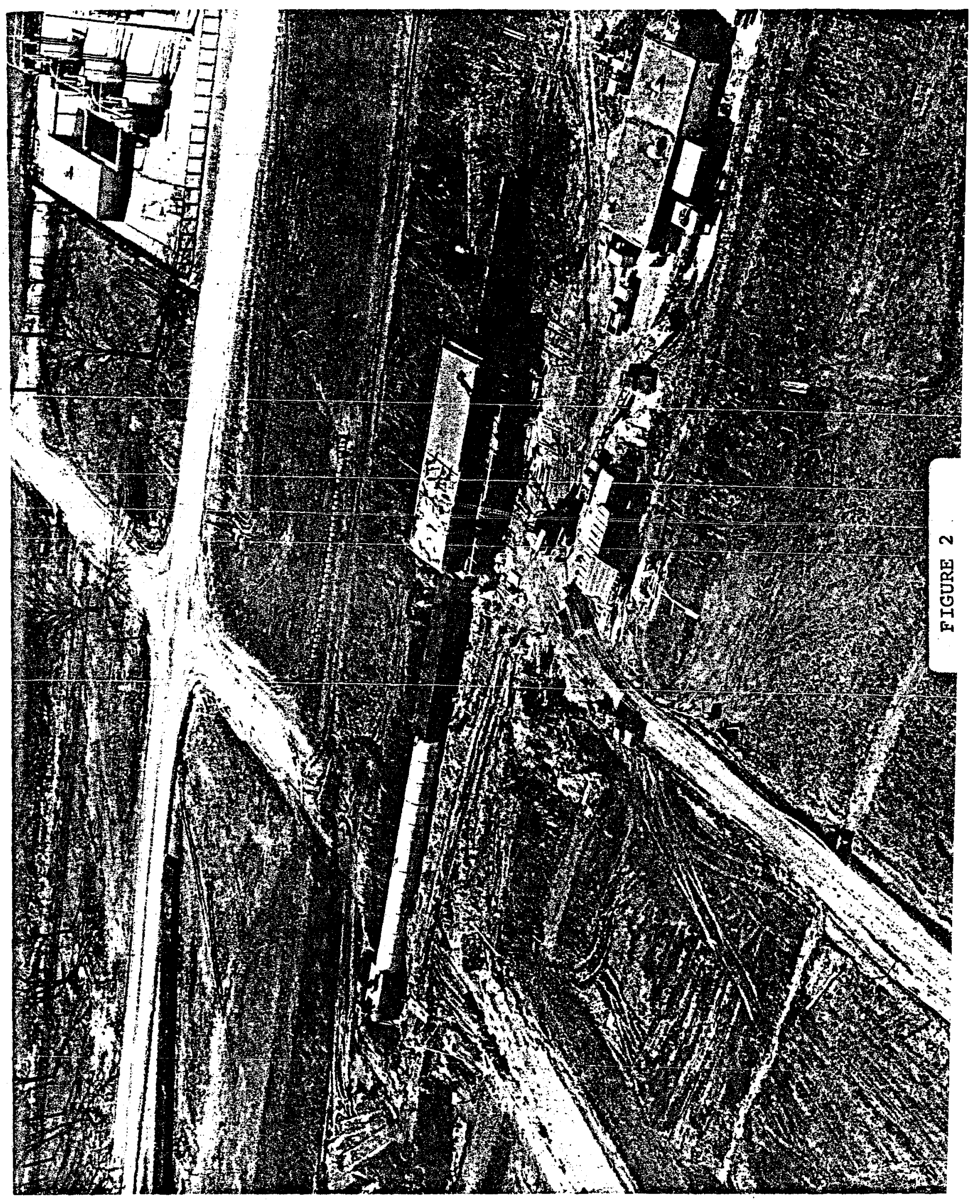




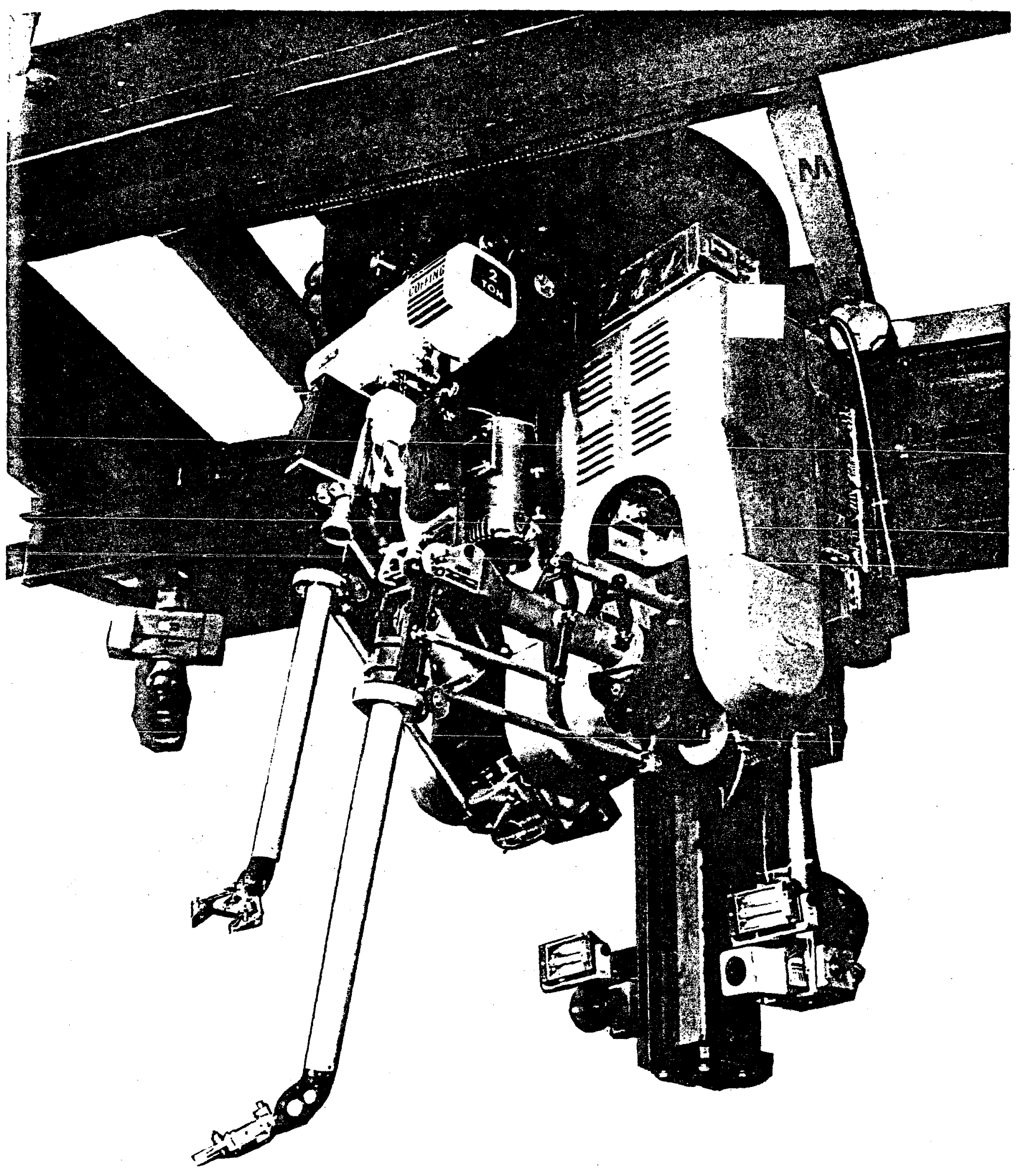




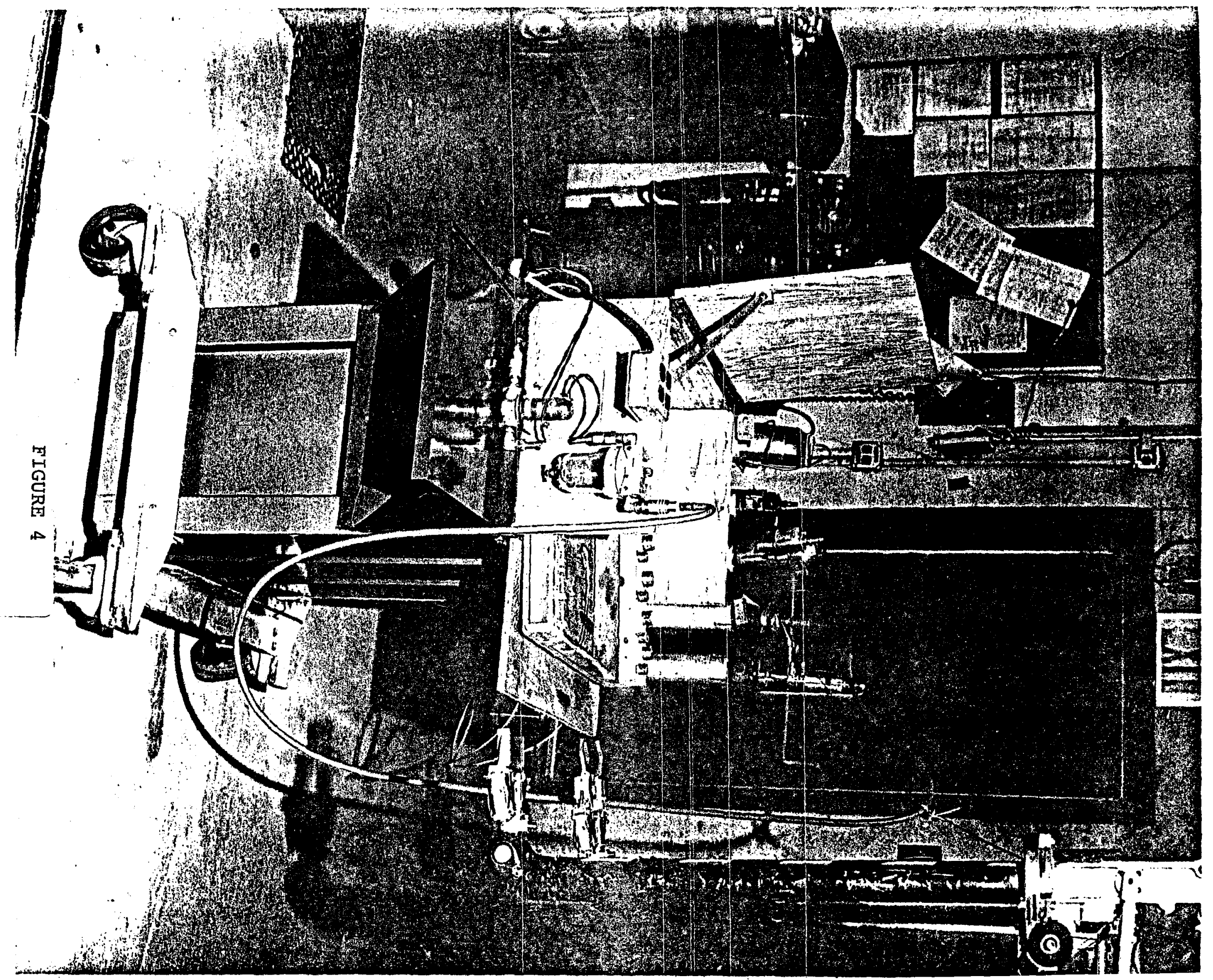




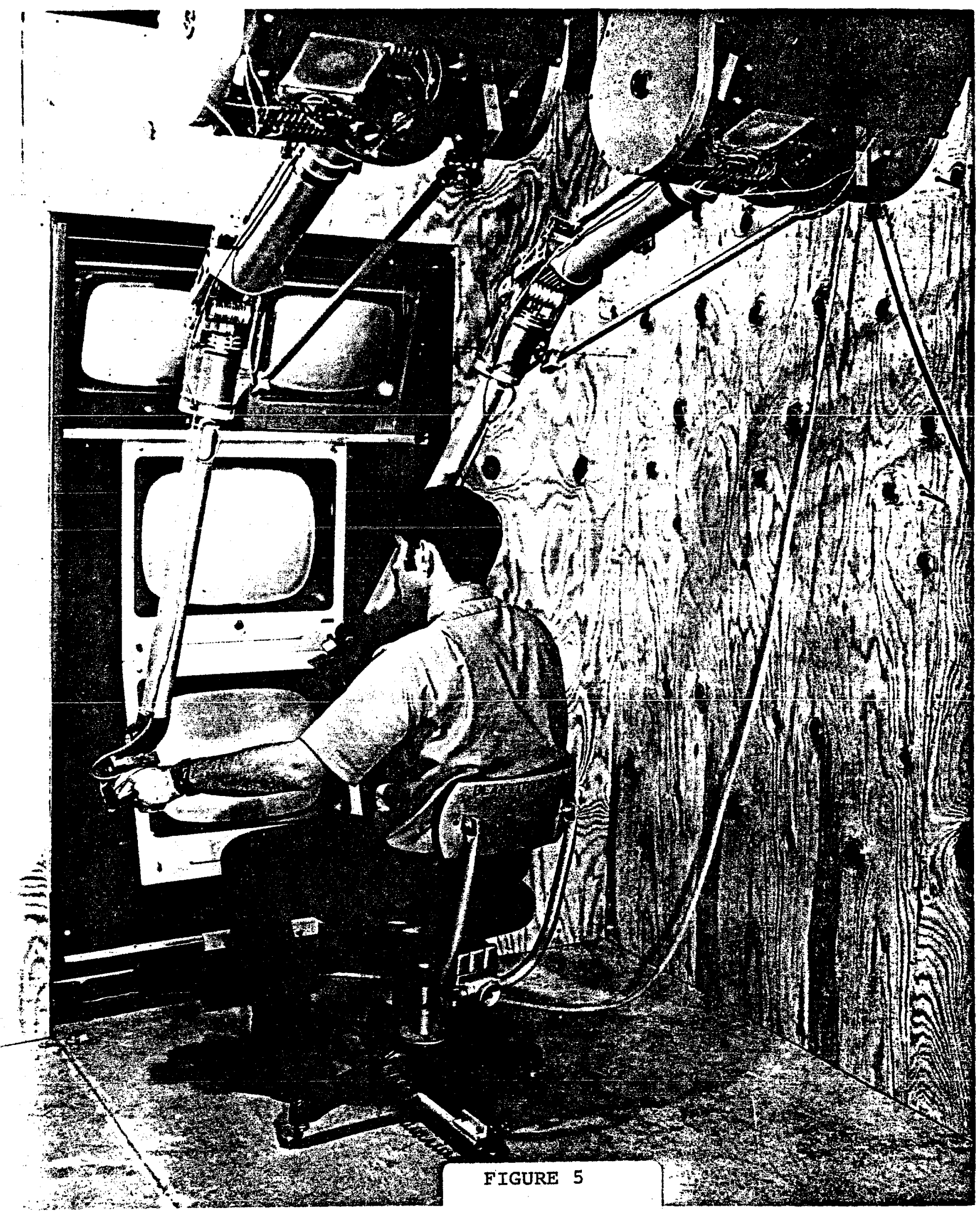




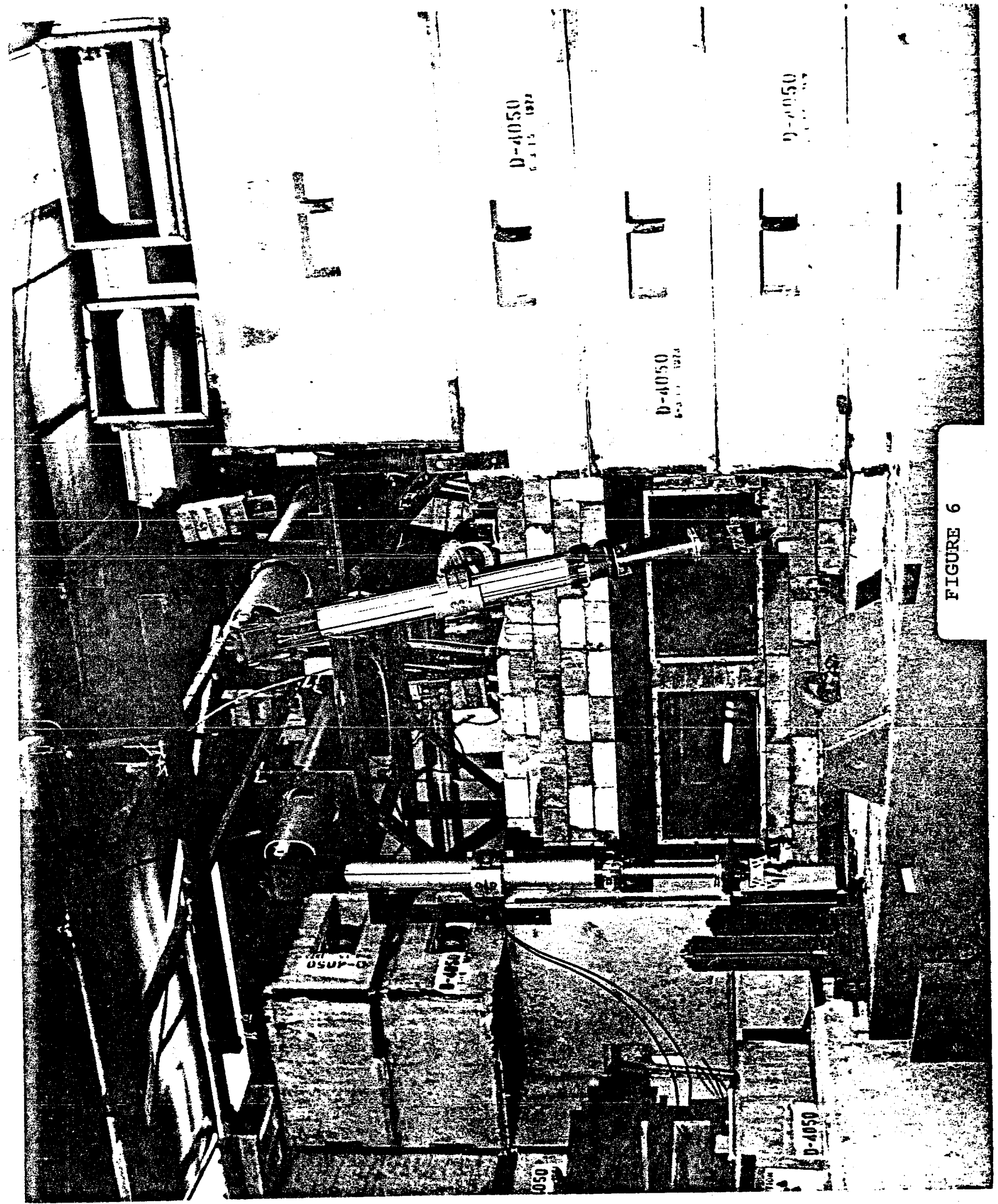




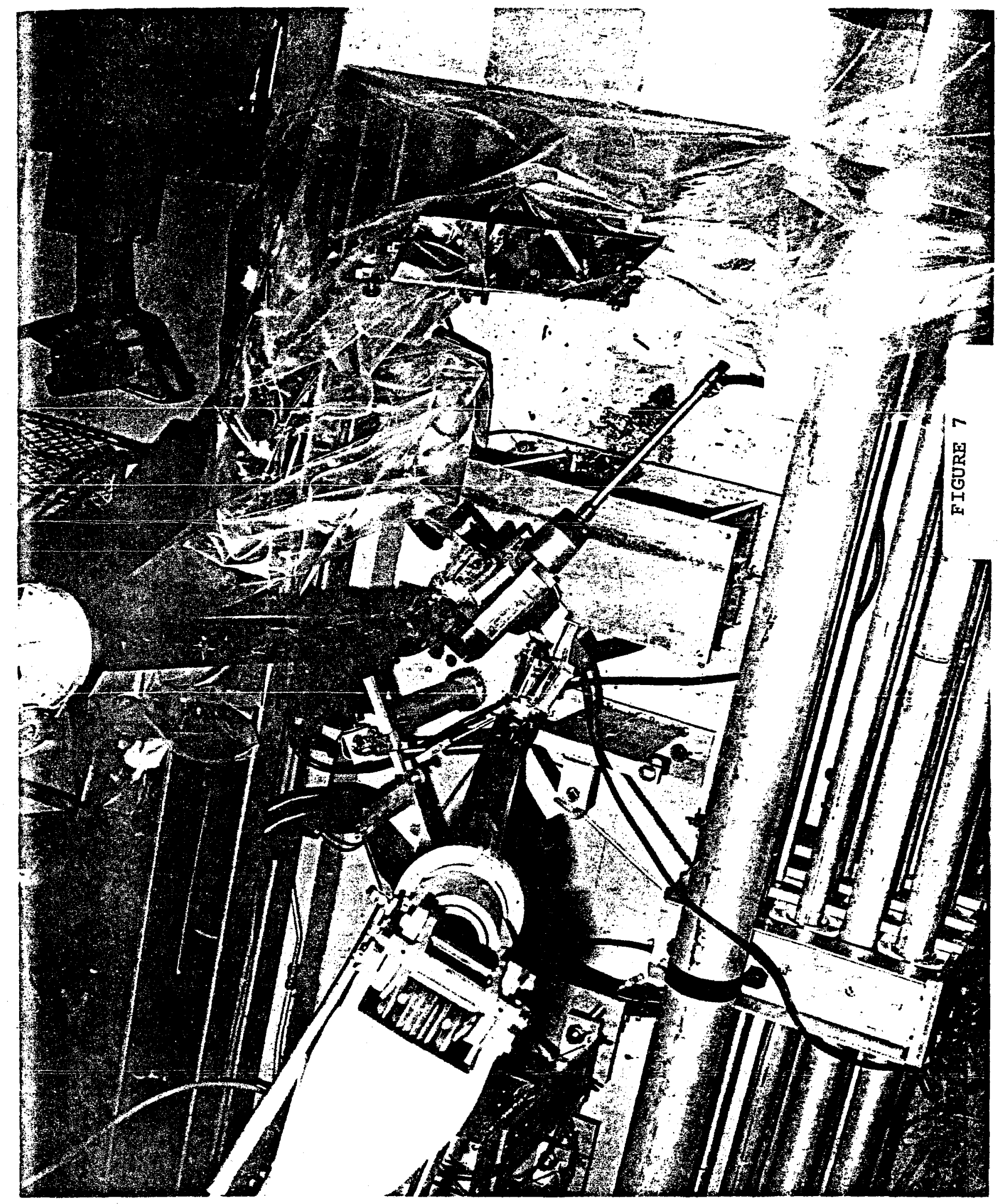

